American Journal of Applied Sciences 3 (9): 2025-2028, 2006

ISSN 1546-9239

(C) 2006 Science Publications

\title{
Design of a Single-Phase Rectifier with Improved Power Factor and Low THD using Boost Converter Technique
}

\author{
Ismail Daut, Rosnazri Ali and Soib Taib \\ School of Electrical Systems Engineering, Kolej Universiti Kejuruteraan Utara Malaysia \\ 02600 Jejawi, Perlis, Malaysia
}

\begin{abstract}
The method of using Boost type of converter was proposed for a $300 \mathrm{~W}$ single-phase rectifier in this paper. By designing the necessary techniques and methodology, the overall Power Factor (PF) and Total Harmonic Distortion would be improved to the expectation. The cause of having low PF and high THD for a diode-capacitor type of rectifiers is related to non-linearity of the input current. Method of re-shaping the input current waveform to be similar pattern as the sinusoidal input voltage is done by the Boost converter and the related controls that act as a Power Factor Correction (PFC) circuit. The results of the designed system were compared against with and without PFC control. The international standard IEC 61000-3-2 on harmonics was used as the reference to determine the performance of the project.
\end{abstract}

Key words: Rectifier, boost converter, active power filter (APF), power factor correction (PFC), power factor (PF), total harmonic distortion (THD), continuous-conduction mode (CCM)

\section{INTRODUCTION}

DC power supplies are extensively used inside most of electrical and electronic appliances in the world today, such as in computers, monitors, televisions, audio sets and others. There are commonly known as rectifiers. The nature of rectifiers either it is conventional or switch mode types, all of them contribute to low PF, high THD and low efficiency to the power system. With the imposed of harmonic standards such as IEC 61000-3-2 by international communities, it would be much important aspect to consider in every design of the appliances.

The objective of this proposal was to develop a circuit with all the necessary components and control system that will in-cooperated into the design of any single-phase rectifier hence, improves the $\mathrm{PF}$ and reduces the current harmonics.

The AC mains utility supply ideally is supposed to be cleaned and free from high voltage spikes and current harmonics in order to ensure good quality and efficient power system harmonics to electronics equipment. Discontinuous input current that exists on the AC mains caused by the non-linearity of the rectification process could be shaped to follow the sinusoidal form of the input voltage.

The process of shaping the input current is done by the Boost converter, which is properly controlled by the related circuitry. The control circuits for this project used low-cost components, easily available yet giving excellent performance and satisfactory results.

\section{Principle of operation}

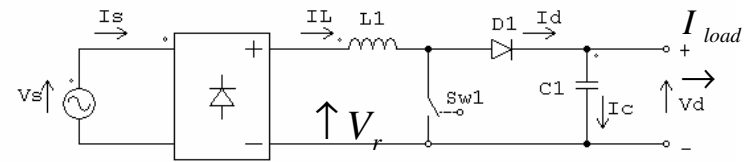

Fig.1a: A rectifier with boost converter

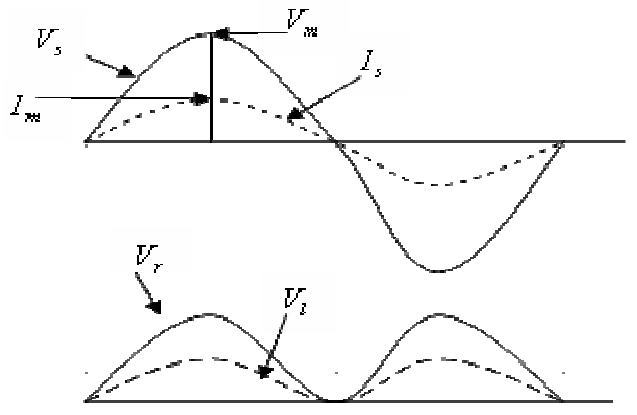

Fig. 1b: Waveforms of related voltages and currents

Figure $1 \mathrm{a}$ and $1 \mathrm{~b}$ above show the basic configuration of a rectifier that uses Boost converter technique as PFC with its respective voltages and currents. For an ordinary rectifier without PFC, the input current $I_{s}$ would be highly non-linear especially when the capacitor $\mathrm{C} 1$ is having large value. By operating the Boost converter in Continuous-Conduction Mode (CCM) as shown in Fig. 2, the input current would be sinusoidal.

Corresponding Author: Ismail Daut, School of Electrical Systems Engineering, Kolej Universiti Kejuruteraan Utara Malaysia (KUKUM), 02600 Jejawi, Perlis, Malaysia, Tel: +604-9798146, Fax: +604-9798304 


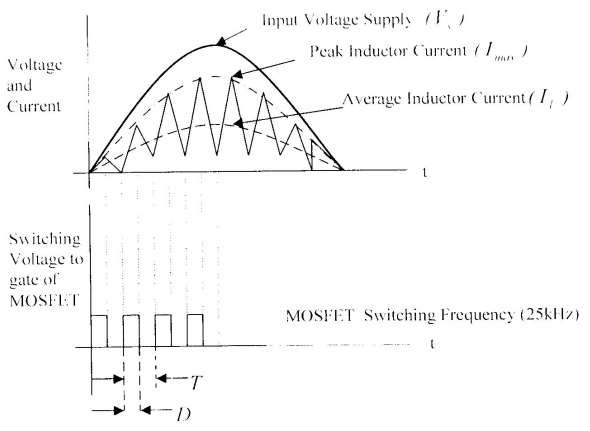

Fig. 2: Voltages and currents in CCM operation

The average output current $I_{\text {load }}$ is given by,

$I_{\text {load }}=\frac{T V_{o}}{2 L} D(1-D)^{2}$

where $T$ is the switching period, $V_{o}$ is the voltage DC output, $D$ is the duty cycle and $L$ is the inductor.

Design concept of the rectifier with PFC

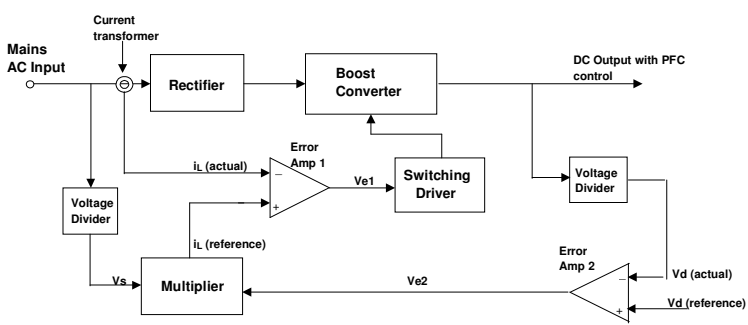

Fig. 3: The PFC control strategy block diagram

The mains AC input voltage is rectified and supplied to the Boost converter, that mainly consists of an inductor, a power MOSFET, a power diode and a bulk capacitor. The Error Amp 2 with predetermined reference voltage senses the DC output voltage across the bulk capacitor. The error voltage Ve2 from the amplifier then is fed to the multiplier and multiplied with the template sinusoidal input voltage to get the reference current, iL(reference). The error Ve1 that is the output of Error Amp 1, as the difference of iL(actual) and iL(reference) provides the correct timing logic for the switching driver circuit to turn on and off the MOSFET in the Boost converter. Hence, this method ensures continuous conduction of current flow for the full cycle of the input voltage. Simulation was done using PSIM ver4.1 and the layout is shown as in Fig. 4

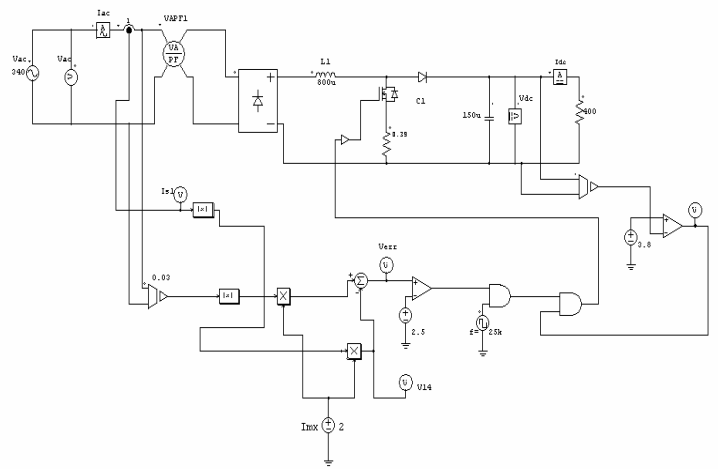

Fig. 4: Simulation layout using PSIM
The simulated results are shown here.
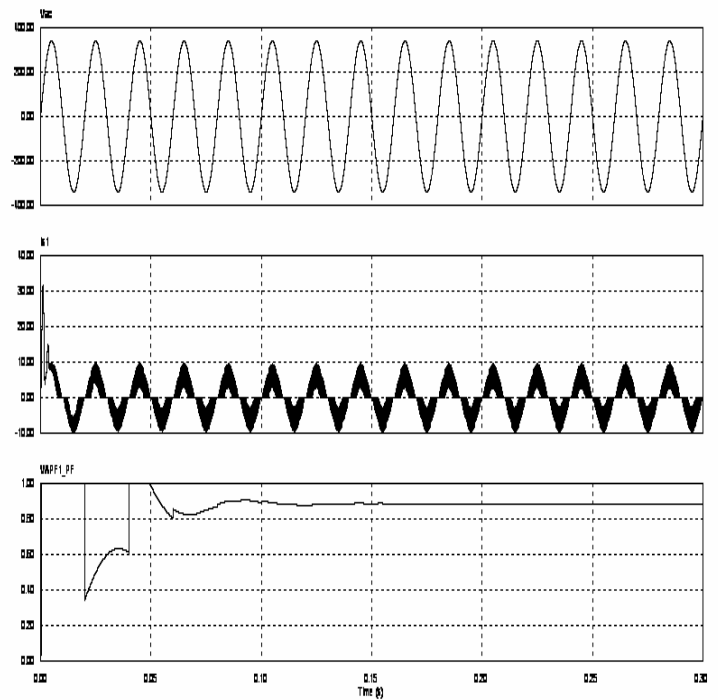

Fig. 5: $\quad$ Input voltage, input current and PF

Through the simulation, the power factor is improved from typical 0.6(without PFC) to 0.88 (with PFC). The shape of the input current (Is1) also likely to follow as the input voltage (Vac). The input current THD is expected to comply with the IEC 61000-3-2 standards.

The rectifier with PFC circuit was developed to realize the performance of the project. Figure 6 shows the complete assembled circuits mounted on printed circuit boards. One is the rectifier unit and the other board is the PFC controller.

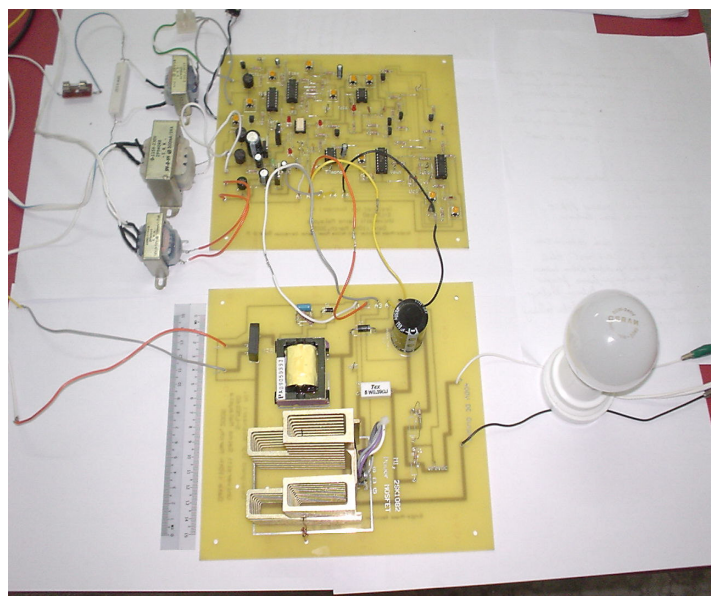

Fig. 6: The rectifier with PFC assembled on PCBs

\section{RESULTS}

The completed project was tested and the results were taken and shown as below. 


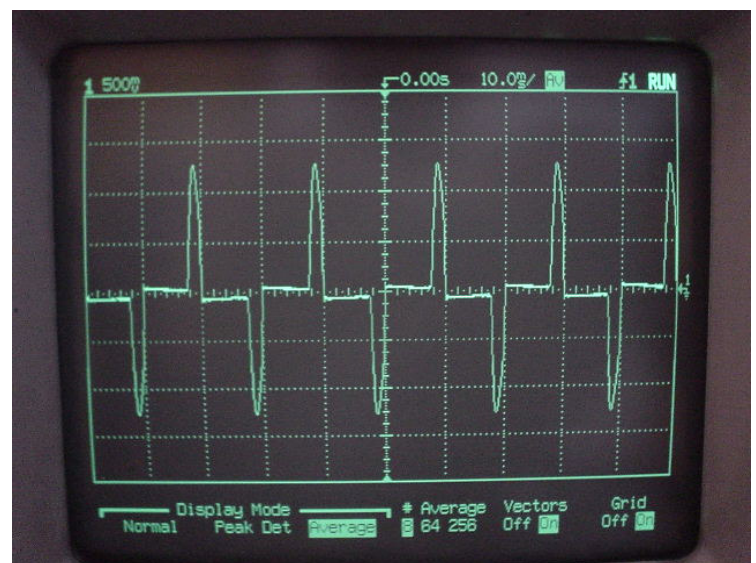

Fig. 7: Input current without PFC

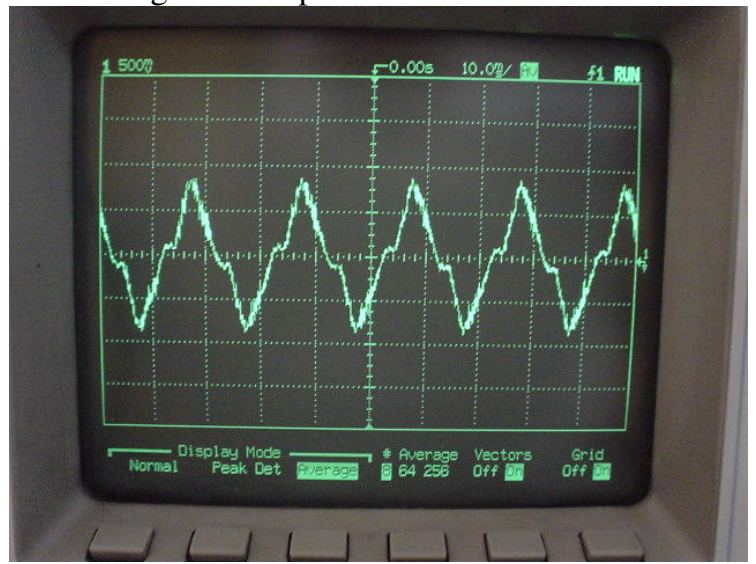

Fig. 8: Input current with PFC

Power factor for the above waveform is 0.88 and input current THD is $52.1 \%$. The PFC-rectifier circuit was tested with maximum load of $300 \mathrm{~W}$. The overall efficiency was $78.6 \%$.

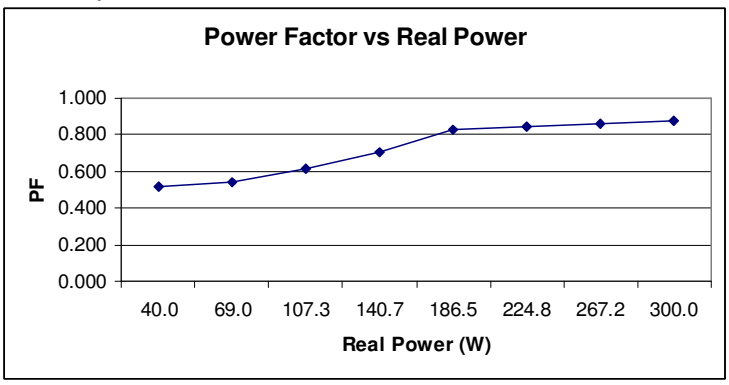

Fig. 9: $\quad$ Trend of PF vs real power

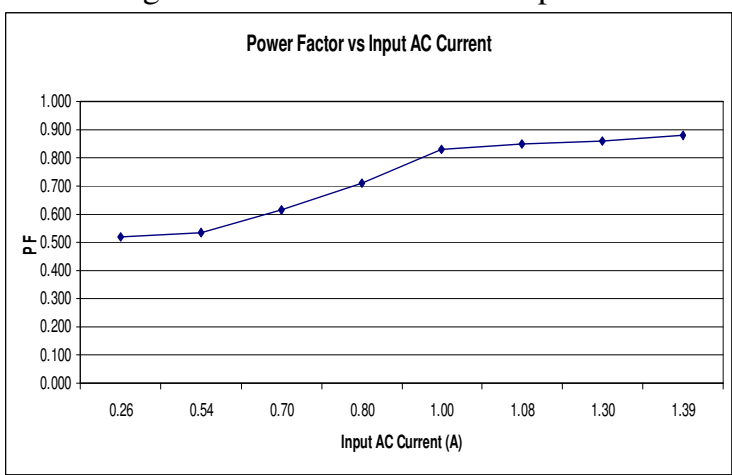

Fig. 10: Trend of PF vs Input current

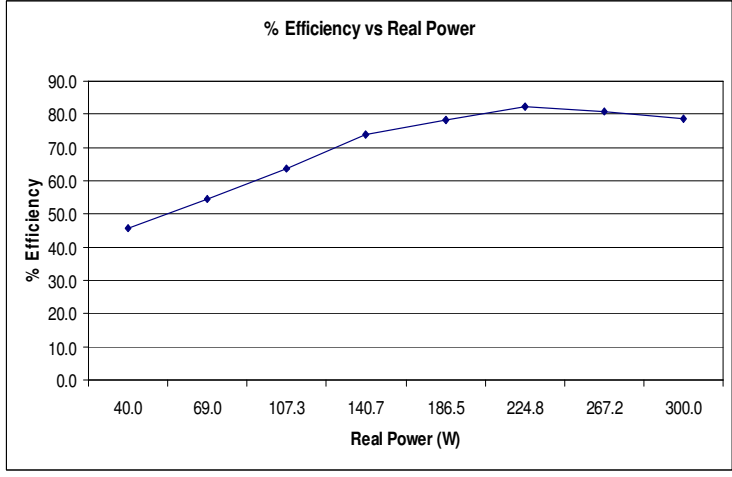

Fig. 11: Trend of efficiency vs real power

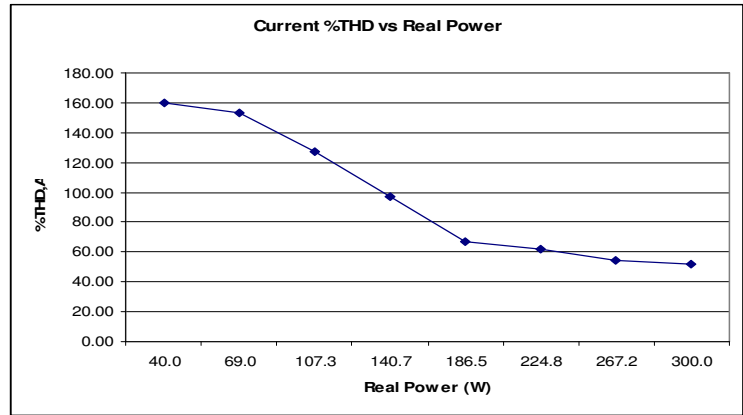

Fig. 12: Trend of THD vs real power

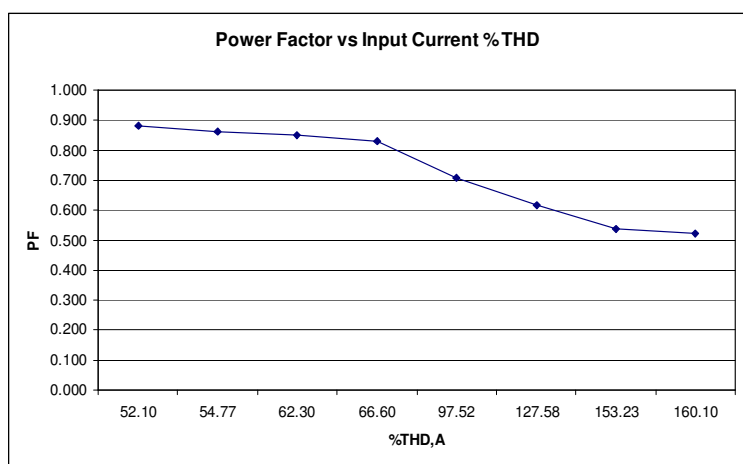

Fig. 13: Trend of PF vs THD

Figure 14 shows the input current harmonic spectrum with respect to the IEC 61000-3-2 harmonic limits for a $300 \mathrm{~W}$ load. Clearly it can be seen that the rectifier with PFC control conforms the IEC 61000-3-2 limits.

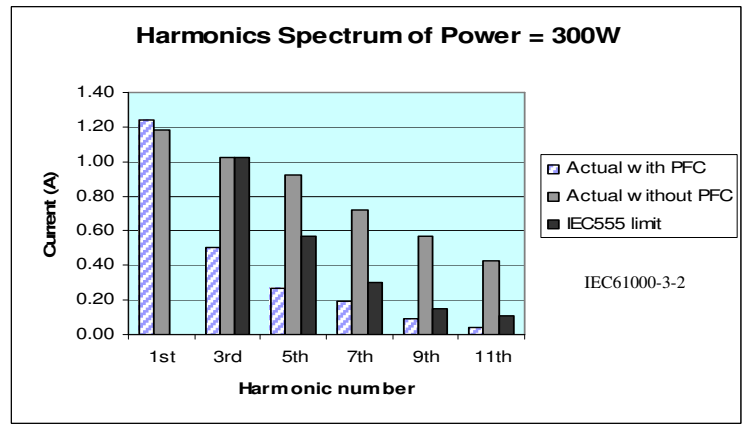

Fig. 14: Input current harmonic spectrum 


\section{DISCUSSION AND CONCLUSION}

From the experimental results, the trends of having better performance are more obvious when the loads are getting heavier. But at lighter loads, the trends do not have significant improvement. The PFC circuitry that controls the Boost converter is having limitation when the load current is smaller. The circuit will avoid the incoming AC current to flow exceeding the load demand, otherwise the energy consumed would be wasted as heat in the MOSFET and inductor.

The PFC circuit can be designed as a pre-converter to any rectifier that needs to be improved in PF and THD, hence complying with the IEC 61000-3-2 standards.

\section{REFERENCES}

1. Ned Mohan, Underland, Robbins, Power Electronics: Converters, Applications and Design. 2nd Edn., pp: 40-43.

2. Muhammad H.Rashid, Power Electronics Circuits, Devices and Applications. 2nd Edn., pp: 303-330.

3. Terry L.M.Bartelt, Industrial Electronics, pp: 65-79.

4. J.Michael Jacob, Applications and Design with Analog IC.

5. Hart, D.W., 1997. Introduction to Power Electronics. Prentice-Hall, pp: 36-44 and 136-200
6. Basu, S. and M.H.J. Bollen, 2005. A novel common power factor correction scheme for homes and offices. IEEE Trans. Power Delivery, 20: 2257-2263.

7. Tao, F.F. and F.C. Lee, 2000. A critical-conduction-mode single-stage power-factor-correction electronic ballast. Applied Power Electronics Conference and Exposition, 2000. APEC 2000. Fifteenth Annual IEEE 1: 603-609.

8. Grigore, V. and J. Kyyra, 2000. A step-down converter with low ripple input current for power factor correction. Applied Power Electronics Conference and Exposition, 2000. APEC 2000. Fifteenth Annual IEEE 1: 188-194.

9. Spangler, J. and A.K. Behera, 1991. Power factor correction techniques used for fluorescent lamp ballasts. Industry Applications Society Annual Meeting. Conference Record of the 1991 IEEE.

10. Round, S.D. and R.M. Duke, 1991. A controlled current inverter for active distortion compensation and power factor correction. Industrial Electronics, Control and Instrumentation. Proceedings. IECON'91. Intl. Conf., 1: 735-740 